\section{Review: addition of salmeterol leads to improved lung function and fewer exacerbations in symptomatic asthma}

\author{
Shrewsbury S, Pyke S, Britton M. Meta-analysis of increased dose of inhaled steroid or addition of salmeterol in \\ symptomatic asthma (MIASMA). BMJ 2000 May 20;320:1368-73.
}

\begin{abstract}
QUESTION: In patients with symptomatic asthma who are currently taking inhaled steroids, does adding salmeterol improve lung function and reduce symptoms and exacerbations compared with increasing the dose of inhaled corticosteroids?
\end{abstract}

Source of funding: no external funding.

For correspondence: Dr S Shrewsbury, Respiratory Clinical Development,

GlaxoWellcome Research E' Development, Five Moore Drive, $P O B$ Box 13398 , Research Triangle Park, $N C$ 27709-3398, USA. Fax +19194838835 . sbs40926@ glaxowellcome.com

\section{Data sources}

Studies were identified by searching EMBASE/Excerpta Medica, Medline, and GlaxoWellcome databases (1985 to Sept 1999).

\section{Study selection}

Studies were selected if they were randomised, double blind, controlled trials comparing the addition of salmeterol to the current dose of inhaled steroid with an increased dose (at least doubling) of the current inhaled steroid for $\geqslant 12$ weeks in adolescents and adults with symptomatic asthma.

\section{Data extraction}

Data were extracted on patient characteristics; treatment type, dose, and duration; and outcome measures based on the intention to treat population. Individual patient datasets were obtained and exacerbation severity was assessed by 2 independent reviewers.

\section{Main results}

9 trials involving 3685 patients met the selection criteria. Mean morning peak expiratory flow (PEF) and forced expiratory volume in one second $\left(\mathrm{FEV}_{1}\right)$ were greater in those who received added salmeterol compared with those treated with an increased dose of inhaled steroids (table 1). Mean percentage of days and nights without symptoms or use of rescue treatment was higher among patients receiving salmeterol (table 2). Total exacerbations and moderate or severe exacerbations were reduced with the addition of salmeterol compared with an increased dose of inhaled steroids (table 3).

\section{Conclusion}

In patients with symptomatic asthma who are currently taking low to moderate dose inhaled steroids (eg, beclomethasone dipropionate, $400 \mu \mathrm{g} / \mathrm{d}$ or equivalent), the addition of salmeterol leads to improved lung function, an increased number of days and nights without symptoms or need for rescue medication, and fewer exacerbations.

Table 1 Mean differences in peak expiratory flow $(P E F)$ and forced expiratory volume in one second $\left(F E V_{1}\right)$ between treatment with salmeterol $v$ an increased dose of inhaled steroids in symptomatic asthma (in favour of added salmeterol) (all $p<0.001$ except * $p<0.01)$

\begin{tabular}{lcc} 
Outcomes & 3 months & 6 months \\
PEF (litre/min) & $22.4(15$ to 30$)$ & $27.7(19$ to 36$)$ \\
\hline FEV $_{1}$ (litre) & $0.10(0.04$ to 0.16$)$ & $0.08(0.02 \text { to } 0.14)^{\star}$ \\
\hline
\end{tabular}

Table 2 Mean percentage (95\% CI) of days and nights without symptoms or use of rescue treatment (in favour of added salmeterol) (all $p<0.001)$

\begin{tabular}{lcc} 
Outcomes & 3 months & 6 months \\
Days without symptoms (\%) & $11(8$ to 15$)$ & $15(11$ to 19$)$ \\
\hline Nights without symptoms (\%) & $5(2$ to 8$)$ & $6(3$ to 9$)$ \\
\hline Days without rescue medications (\%) & $16(13$ to 20$)$ & $19(14$ to 24$)$ \\
\hline Nights without rescue medications $(\%)$ & $9(5$ to 12$)$ & $9(5$ to 13$)$ \\
\hline
\end{tabular}

Table $3 \geqslant 1$ exacerbations of asthma according to severity between treatment with salmeterol and increased dose of inhaled steroid

\begin{tabular}{lll}
\hline Outcomes & $\begin{array}{l}\text { ARR favouring salmeterol } \\
(95 \% \mathrm{Cl})\end{array}$ & NNT (Cl)† \\
\hline Any exacerbation & $2.7 \%(0.4$ to 5.04$)$ & $37(20$ to 233$)$ \\
\hline Moderate or severe exacerbation & $2.4 \%(0.2$ to 4.6$)$ & $41(22$ to 417$)$ \\
\hline
\end{tabular}

$\dagger$ Abbreviations defined in glossary; $\mathrm{\dagger Cl}$ calculated from data in article.

\section{COMMENTARY}

Despite the use of inhaled corticosteroids, many asthma patients continue to experience symptoms. The meta-analysis by Shrewsbury et al concludes that in patients experiencing symptoms despite using low to moderate doses of inhaled corticosteroids, the addition of salmeterol (a long acting $\beta_{2}$-agonist) is more effective than increasing the dosage of inhaled steroids. Readers should be alert to the fact that all 9 included studies were sponsored by GlaxoWellcome, that 2 of the 3 authors are company employees, and that GlaxoWellcome manufactures Serevent (salmeterol xinafoate).

Patients showed an increase in lung function as evidenced by improvements in PEF and $\mathrm{FEV}_{1}$ at 3 and 6 months. The authors explain, however, that these findings are not surprising given that in most of the studies, a requirement for study entry was a demonstrable, clinically relevant response to $\beta$-agonists. For all exacerbations, the number needed to treat was 37 , which means that the addition of salmeterol to treatment with inhaled steroids in 37 patients with symptoms would prevent one exacerbation in one additional patient, compared with at least doubling the dosage of inhaled steroids.

The review supports a decision to add inhaled salmeterol instead of doubling or tripling the current dose of inhaled corticosteroids for individuals with asthma who continue to experience symptoms despite regular use of inhaled corticosteroids. This is an important option given the potential side effects of high dose inhaled steroids, patients' fears about the use of inhaled steroids, and the desire to identify the lowest dose of inhaled steroids needed. This observation is consistent with the recommendations of current asthma guidelines. ${ }^{12}$ It is important to remember that salmeterol is not intended as monotherapy for asthma because of its lack of anti-inflammatory properties.

Lisa Cicutto, RN, PhD, ACNP Assistant Professor, University of Toronto Acute Care Nurse Practitioner-Respirology University Health Network, Toronto, Ontario, Canada

1 Boulet LP, Becker A, Berube D, et al. Canadian asthma consensus report, 1999. Canadian Asthma Consensus Group. CMAJ 1999;161:S1-61.

2 National Asthma Education and Prevention Program. Guidelines for the diagnosis and manHuman Services; 1997. agement of asthma: expert panel report 2. Bethesda, MD: US Department of Health and 